\title{
Gestão de recursos humanos em bibliotecas universitárias: reflexões
}

\author{
Júlia Gonçalves da Silveira \\ Doutora em ciência da informação. Professora Adjunta da UFMG. Escola de Ciência da Informação. Departamento de Organização e \\ Tratamento da Informação. \\ E-mail: juliags2@hotmail.com
}

\section{Resumo}

Apresenta os resultados de uma revisão de literatura feita sobre gestão de recursos humanos em bibliotecas universitárias com o objetivo de conhecer a situação atual apresentada por alguns estudiosos da área, assim como contribuir para melhoria da performance dos administradores de unidades de informação atuantes no contexto acadêmico.

A realidade estudada, nos trabalhos selecionados para análise, sugere mudanças de posturas no desempenho dos gerentes das bibliotecas universitárias nacionais, assim como na maneira de as organizações considerarem seus subsistemas. Recomenda tanto aos bibliotecários quanto às instituições universitárias assumir uma postura mais efetiva relacionada aos investimentos em atividades de capacitação, aperfeiçoamento e qualificação, para que tenham condições de implementar serviços e produtos de informação científica e tecnológica mais adequados às demandas e necessidades da comunidade, especialmente da universitária. Sugere, ainda, aos gerentes das bibliotecas universitárias, que assumam posturas mais efetivas, relativas a posicionamentos políticos e humanitários perante a nova ordem econômica mundial, na qual aspectos sociais, culturais e humanos tendem a ocupar espaços secundários.

\section{Palavras-chave}

Gestão de recursos humanos. Gestão de pessoas. Gestão de capital humano. Gestão de bibliotecas universitárias. Gestão de bibliotecas acadêmicas.

\section{Management of human resources in university libraries: reflections}

\begin{abstract}
s
The results of a literature review about human resources management at university libraries are brought out here for the purpose of knowing the present situation presented by some scholars in this area, as well as contributing to the betterment of the performance of managers of information units operating in this academic context. The reality studied through selected works for analysis suggests changes in the positions concerning the performance of managers of the national university libraries, as well as in the way of how the organizations take into consideration their subsystems. It is recommended that both the librarians and university institutions take up a more effective position as regards investments in activities of capacity, improvement and qualification. So better conditions should be held for implementing services and products of scientific and technological information fitting better for the demands and needs of especially the academic community. It is furthermore suggested that the university library managers may take up a more effective attitude in relation to the political and humanitarian positions before the new economic world order, in which social, cultural and haman aspects are placed in a second plan.
\end{abstract}

\section{Keywords}

People management. Human capital. Human resources management. University libraries management. Academic libraries management. 


\section{INTRODUÇÃO}

O fenômeno atual de globalização, que preconiza e pressiona organizações educacionais, em escala mundial, a serem predominantemente competitivas, eficazes e rentáveis é fator que deve ser motivo de reflexão dos administradores de bibliotecas.

Sob a ótica da nova ordem econômica mundial, a educação é considerada essencialmente uma fonte de despesas. Condições sociais, culturais e humanas tendem a ocupar espaços secundários e, muitas vezes, totalmente excluídas dos elencos de prioridades instituídas ou legitimadas por aqueles países ou indivíduos que dominam outros em aspectos relativos às condições econômicas e culturais (SANTOS, 2001).

As pessoas ou capital humano, como cognominadas na atualidade, constituem elementos essenciais para as organizações, sendo da competência dos seus gestores a criação e a manutenção de condições ideais nos seus respectivos ambientes de trabalho (TACHIZAWA; FERREIRA; FORTUNA, 2001).

Aos gestores ou administradores das bibliotecas universitárias, cabe, entre outras funções gerenciais, o estabelecimento de relações positivas com sua equipe de trabalho, favorecendo e estimulando o alcance de objetivos comuns entre pessoas e organizações (SILVA, 2000; XUDONG, 2006).

As bibliotecas universitárias são agências sociais criadas para fomentar o alcance de atividades fim das universidades. Devem se empenhar para alcançar objetivos e cumprir metas organizacionais e sociais relacionadas ao ensino, pesquisa e extensão. Em contrapartida, devem atender a expectativas de sua comunidade interna de trabalhadores, ou seja, de seu diversificado quadro de funcionários, de modo a favorecer a qualidade de vida e satisfação no ambiente de trabalho.

Em decorrência da complexidade do tema, assim como pela impossibilidade de abordar todos os aspectos envolvidos na questão em um só artigo, buscou-se apresentar e chamar à reflexão alguns pontos considerados recorrentes na totalidade da literatura analisada para a construção deste trabalho, o qual se enquadra na tipologia de pesquisa de análise teórica.

Constitui objetivo deste artigo, portanto, apresentar uma síntese de estudos feitos sobre a problemática de gestão de recursos humanos ou de pessoas em organizações de modo geral e em bibliotecas universitárias, de modo especial.

Sob outra ótica, pretende-se divulgar e compartilhar os estudos feitos, no intuito de contribuir para melhoria da performance dos administradores de unidades de informação ou, mais especificamente, gestores atuantes em contextos de bibliotecas acadêmicas ou universitárias, provavelmente preocupados com essa questão, que se considera de extrema relevância para o campo de ciências sociais, incluindo aí as áreas de biblioteconomia e ciência da informação.

\section{RESULTADOS DO ESTUDO DA LITERATURA}

\section{Bibliotecas universitárias}

Considerada um dos pilares da vida acadêmica, as bibliotecas universitárias têm por função essencial subsidiar as atividades de ensino, de pesquisa e de extensão desenvolvidas nas universidades, mediante a provisão de recursos informacionais seletivos, diversificados e organizados.

Apesar da sucinta expressão que tenta descrever, em poucas linhas, a função primordial desses órgãos, considera-se de extrema complexidade tanto seu papel quanto sua administração. Complexidade essa proveniente da diversidade, pluralidade de segmentos que devem ser atendidos da forma mais conveniente possível e, também, das interferências inerentes à sua condição de subsistema, condicionado às vertentes e forças políticas internas e externas, muitas vezes conflitantes e adversas. 
Como destacado por Almeida (2008, p. 57):

essa organização é corresponsável pelo avanço científico e tecnológico ocorrido nos últimos tempos [...] faz parte de uma organização maior [...] as pessoas envolvidas na equipe desse tipo de organização necessitam acompanhar e, de preferência, estar à frente das mudanças que possam ocorrer em seu ambiente [...] nas organizações, cada trabalhador é responsável por uma ou mais atividades, e para que ele continue a realizar tais atividades, é preciso seguir aprendendo [...].

A educação de nível superior mundial e nacional tem sido conclamada a corresponder a anseios sociais e pressões políticas das mais diversas ordens, neste limiar do século 21. Aspectos referentes à inclusão e ampliação de vagas e criação de novos cursos; reestruturações de projetos pedagógicos e de métodos docentes, reformas da legislação que rege o ensino superior, estabelecimento de parcerias internas e externas, melhoria da qualidade do ensino visando especialmente a fomentar uma aprendizagem ao longo da vida, entre outras questões, constituem ordem do dia nas discussões de órgãos colegiados das universidades, temáticas de eventos e de artigos de publicações científicas (MACEDO et al., 2005; ORGANIZACIÓN..., 2005; MICHELOTTO; COELHO; ZAINKO, 2006; BERTOLIN, 2007).

As bibliotecas universitárias mundiais têm sido chamadas a atender a apelos da mesma ordem, já que constituem subsistemas universitários, devendo estar aptas e dispostas a construir novos modelos estruturais, de modo a alcançar uma posição de destaque, na condição de sistema que deve favorecer a pesquisa, a construção de fontes de informação científica, a divulgação do conhecimento e a aprendizagem, acrescentada de sua função de prestação de serviços extensionistas (ODDONE, 1998; HARBOE-REE, 2007; BARRIONUEVO ALMUZARA, 2008).
Obviamente, para atingir os objetivos e cumprir as metas que visam ao cumprimento das novas diretrizes, há necessidade de visão gerencial proativa por parte dos gestores das bibliotecas acadêmicas ou universitárias, que leve à elaboração e ao estabelecimento de planos estratégicos que priorizem a formação de recursos humanos que irão atuar em ambientes mutáveis, que estejam capacitados para a convivência com novas situações, que saibam superar o empirismo e que busquem suporte teórico em áreas interdisciplinares, que possam auxiliá-lo a atuar em todos os campos, nos quais a informação e o conhecimento forem objetos de ação.

No decorrer deste trabalho serão apresentados os resultados de alguns estudos teóricos, inclusive publicados entre as décadas de 1980 e 90. Eles podem auxiliar a compreensão e contribuir para o enfrentamento de alguns dos desafios que se colocam contemporaneamente no caminho profissional dos gestores organizacionais da era informacional (após 1990) focada, segundo Chiavenato, (2000) na tecnologia da informação, na globalização, nos serviços, na aceleração de mudanças, na imprevisibilidade, na instabilidade e incerteza e com ênfase na produtividade, na qualidade, na competitividade, no cliente e na globalização.

Adotar significados da sociedade do conhecimento, apresentados pela Organización de las Naciones Unidas para la Educación, la Ciência y la Cultura (Unesco) (2005), envolve uma reflexão em torno da vertente que "sociedade do conhecimento compreende dimensões sociais, éticas e políticas muito mais amplas", do que simplesmente se ater aos aspectos relacionados aos progressos tecnológicos atuais. A sociedade da informação idealizada implica trabalhos compartilhados e cooperativos em prol de uma sociedade mais consciente dos problemas que afetam a humanidade, usando a informação e o conhecimento para o desenvolvimento coletivo, enfim para efetivar processos de comunicação e de autoaprendizagem. Conforme Rendón Rojas (2007, p. 11), uma sociedade do conhecimento deveria 
garantir o compartilhamento do saber, a integração de cada um de seus membros, além de promover novas formas de solidariedade com as gerações presentes e futuras, e sequer admitir a existência de marginalizados.

\section{Gestão de recursos humanos em organizações e bibliotecas universitárias}

Messeder (1989, p. 50) chama a atenção para o atraso da área de administração de recursos humanos em nosso país e considera que na maioria das empresas brasileiras predomina uma "administração de recursos humanos cartorial e burocrática, com pouca ou nenhuma preocupação com o desenvolvimento/ crescimento individual e profissional."

A busca de economia, eficiência e racionalidade é questão fundamental para qualquer organização, na medida em que ela dificilmente sobreviverá, caso não considere esse princípio indiscutível da administração.

Entretanto, afirma o autor, "há necessidade de se dar mais atenção às vertentes científicas que construíram o universo conceptual da administração de recursos humanos". Nesse sentido, ressalta Messeder, precisamos

"[...] conscientizar-nos de que o homem está no centro de tudo e que as estruturas organizacionais são estabelecidas para servirem de instrumento à realização humana, portanto, deverão estar a seu serviço e não contra ela" (MESSEDER, 1989, p. 60).

Referindo-se à situação de crise e instabilidade constante no país, que parece acentuar os conflitos, tensões e pressões ambientais nas relações sociais e humanas nas organizações, Messeder considera que as questões como participação, inovação tecnológica e outras que afetam as relações de trabalho internamente devem ser objeto de preocupação constante do administrador, cujo papel deveria ser redimensionado

Ci. Inf., Brasília, v. 38, n. 2, p. 126-141, maio/ago. 2009 "levando-se em conta que a ele cabe a tarefa de harmonizar o processo de mudança organizacional, mais comprometido com os aspectos sociais e não somente com o seu equipamento instrumental e tecnológico".

Com relação à participação intraorganizacional, o autor observa que não se pode desvincular dessa questão o processo mais amplo de participação social. Afirma que

"é nas organizações que se acentua o processo de exploração e de supressão dos direitos sociais e culturais, a partir da divisão do trabalho, da distribuição do poder e da riqueza e das desigualdades inerentes a esse processo" (MESSEDER, 1989, p. 56).

Outro fator que influencia as relações de trabalho, lembrado por Messeder, e que não poderia ser desconsiderado pela administração de recursos humanos das organizações atuais, diz respeito ao impacto causado pelo processo de inovação e de obsolescência rápida das tecnologias que afetam tanto a natureza quanto os processos de trabalho:

nesse aspecto, parece-nos que a administração de recursos humanos tem importante papel a desempenhar. Existe grande expectativa com relação a novas políticas de recursos humanos que facilitem e agilizem os esforços de treinamento e desenvolvimento de grandes contingentes de mão-de-obra. Nesse particular, grandes alterações deverão ser feitas no conteúdo dos programas, pois maior preocupação com o planejamento e a avaliação se tornará uma exigência dos novos tempos (MESSEDER, 1989, p. 59).

Em resultados de estudos da literatura nacional relatados em dissertação apresentada e defendida junto ao curso de Mestrado em ciência da informação/Administração de Bibliotecas, Silveira (1991) constatou que poucos foram os trabalhos que abordaram as bibliotecas universitárias sob sua condição de agências sociais que agregam 
pessoas que devem ser gerenciadas por líderes adequadamente preparados em áreas pertinentes ao campo de administração de recursos humanos.

A literatura de biblioteconomia e ciência da informação ressalta a necessidade de mudança de atitude do bibliotecário para que ele se enquadre ao perfil desejável do profissional de informação demandado pela sociedade.

Entre alguns itens referentes ao perfil desejável desse profissional, são encontradas diversas menções para que ele seja criativo, dinâmico, eficiente. No âmbito interno das bibliotecas, essas características dizem respeito ao perfil ideal tanto dos seus gestores quanto das outras pessoas que compõem o seu quadro de pessoal.

Quanto aos gerentes, precisam ter conhecimentos diferenciais e se qualificar para atuar em áreas fundamentais ao desenvolvimento harmonioso das bibliotecas universitárias, incluindo o planejamento organizacional, financeiro, de outros recursos físicos e humanos. Devem assumir a responsabilidade pela gestão de atividades específicas e complexas, como formação e desenvolvimento de pessoas e coleções; tratamento técnico dos documentos e de recursos de informação de modo geral; inclusão de novas tecnologias e de novas metodologias que facilitem o trabalho e acesso à informação; fomentar ações que objetivem a educação e formação de habilidades de uso da biblioteca e de seus recursos informacionais em sua comunidade de usuários; integrar o setor em atividades cooperativas e extensionistas, entre outras.

Fiúza, Paim e Ferreira (1987, p. 52), em uma proposta para cursos de especialização em administração de bibliotecas universitárias, afirmam que habilidades gerenciais se adquirem a partir do conhecimento das bases teóricas de administração e destacam a necessidade de "conhecer vários tipos de estilos gerenciais e desenvolver a capacidade de sintetizá-los e aplicá-los a uma instituição específica".
Tendo-se em vista o êxito de suas funções na universidade, os gerentes deverão considerar, como um dos pontos básicos do planejamento das bibliotecas universitárias, a formação e a qualificação de seus recursos humanos, a começar pelo cuidado com a própria condição de administrador. Nesse sentido, deve dominar conhecimentos específicos da área gerencial e transformá-los em boas práticas, visando tanto ao desenvolvimento organizacional, quanto ao de sua equipe de trabalho.

Estariam as bibliotecas universitárias brasileiras favorecendo o desenvolvimento individual e profissional dos bibliotecários nelas atuantes?

Robredo e Cunha (1986, p. 17) destacam que há necessidade de o bibliotecário possuir conhecimentos interdisciplinares e ser flexível para se adaptar "às exigências de um mercado que evolui e se 'tecnifica' com grande rapidez". Consideram que áreas de interesse dominante do bibliotecário resultariam da convergência de três grupos principais de disciplinas: teoria da informação, incluindo a cibernética, a linguística, a lógica formal, etc.; técnica da informação, incluindo a engenharia elétrica e eletrônica, a programação de computadores, etc.; funções ou atividades de prestação de serviços, que incluiria a gerência de bibliotecas e centros de informação.

Neves (1986) também aponta o caráter interdisciplinar da biblioteconomia que, como outras áreas sociais aplicadas, não subsiste por si mesma, devendo beneficiar-se de técnicas e metodologias de outros campos do conhecimento, de modo a exercer sua prática de maneira eficaz, incluindo administração, estatística, psicologia social, ciências econômicas, pedagogia, filosofia e ciência da computação.

Abordando a questão referente às atividades de treinamento ou aperfeiçoamento utilizadas por 477 bibliotecários acadêmicos, Pasquarelli (1987) mostra que esses profissionais frequentam 
preferencialmente cursos de extensão universitária, em detrimento das etapas de especialização, mestrado e doutorado. A autora pondera que os cursos de curta duração oferecem baixo grau de aproveitamento, pois geralmente apresentam "os assuntos superficialmente."

Ao analisar diversas barreiras que inviabilizam o processo de transferência de informação nas bibliotecas universitárias nacionais, Santana (1989) afirma que essas instituições, embora detentoras dos maiores e melhores acervos em ciência e tecnologia, e tendo, como usuários,

"uma clientela potencialmente das mais importantes para o país, não dispõem dos mínimos recursos para a consecução de sua principal finalidade: a transferência da informação".

A autora considera que, geralmente, o bibliotecário acadêmico não está capacitado para contribuir no sentido de reverter a situação de inoperância dessas bibliotecas, e enfatiza a necessidade de ele se "conscientizar sobre a função social da biblioteca universitária e da sua própria”. Santana considera, ainda, que a universidade necessita assumir uma postura mais efetiva com relação a programas de capacitação e aperfeiçoamento contínuo do bibliotecário, para que ele tenha condições de implementar serviços de informação científica e tecnológica mais adequados às demandas e necessidades da comunidade.

Rozados (2007), em trabalho apresentado durante o 2ํㅡㄹ Congreso Brasileiro de Bibliotecología, realizado na cidade de Buenos Aires, atenta para a importância que deve ser dada à educação continuada, a fim de que os profissionais bibliotecários obtenham conhecimentos relacionados à educação para o trabalho. Alega, a autora, que o aprendizado contínuo favorecerá o atendimento "tanto das necessidades das organizações quanto as pessoais". Destaca o conceito de educação contínua como "processo de formação constante, de aprender

Ci. Inf., Brasília, v. 38, n. 2, p. 126-141, maio/ago. 2009 sempre, de aprender em serviço, juntando teoria e prática, refletindo sobre a própria experiência, ampliando-a com novas informações e relações". A autora apresenta ainda o conceito de organizações que aprendem, de Peter Senge, registrado em seu livro A quinta disciplina:

[...] aquela nas quais as pessoas expandem continuamente sua capacidade de criar resultados que realmente desejam, onde surgem novos e elevados padrões de raciocínio, onde a aspiração coletiva é libertada e onde as pessoas aprendem continuamente a aprender em grupo.

Abordando o problema de gerência de ideias novas na organização moderna, que se vê diante de mudanças rápidas, nas quais demandas de conhecimentos e habilidades necessárias já não são facilmente previsíveis, Motta (1989) considera a criatividade como um "recurso existente em todos os seres humanos". Afirma que "as organizações deveriam criar condições para que os indivíduos liberem seu potencial criativo e promovam as inovações" necessárias e adaptativas a novas circunstâncias.

O autor sugere que as organizações projetem tarefas e funções que se constituam em desafios e pressões para o aumento da criatividade do indivíduo, interferindo em sua atuação profissional. Para que os desafios estimulem a criatividade, Motta esclarece que o trabalho na organização deve representar "desafio para o alcance de resultados, mas que também proporcione suficiente autonomia individual para imaginar, desenhar e criar alternativas de produção e de comportamento administrativo".

Sendo a criatividade uma característica potencial nos indivíduos e um recurso altamente disponível nos ambientes organizacionais, o autor ressalta que os gerentes devem desenvolver habilidades criativas de todos os membros da organização, o que considera mais importante do que "institucionalizar grupos de pensadores sofisticados, para desenvolver habilidades criativas". 
Motta considera a inovação para a solução dos problemas que se apresentam nas organizações um processo complexo porque envolve a alteração de crenças, de hábitos e de interesses individuais e coletivos sedimentados. Destaca, em contrapartida, que compete ao gerente ou administrador estimular a criatividade individual, despertando no indivíduo o espírito crítico e oferecendo as oportunidades de descobrir e conhecer novas possibilidades e alternativas.

Considerando a inovação como processo organizacional coletivo, "onde ideias individuais, únicas, precisam ser coletivizadas e institucionalizadas", Motta defende a importância de mobilização de todos os recursos existentes na organização, em prol da criação de condições favoráveis e superação de eventuais resistências, a fim de impulsionar mudanças julgadas positivas, benéficas a determinada organização.

$\mathrm{O}$ autor citado salienta que a teoria organizacional moderna, além de considerar o comportamento administrativo dos indivíduos, componentes de uma organização, a partir de alguns fatores de socialização externa (características individuais aprendidas fora da ambiência de trabalho) e de sua própria capacidade individual (enquanto agente potencial de mudança), pode ser influenciada ou explicada com base nas próprias condições organizacionais:

[...] na perspectiva comportamental, a teoria organizacional moderna é altamente baseada na premissa de que são as organizações, e não os indivíduos, os grandes responsáveis pela ineficiência e ineficácia que se pode constatar na ambiência organizacional. Essa responsabilidade é diretamente vinculada à falha das organizações em proporcionar a seus funcionários oportunidade razoável de crescimento e desenvolvimento pessoal e profissional. Assim, dificuldades administrativas devem ser procuradas menos na competência técnica da instituição ou na ineficiência individual, e mais nas condições oferecidas pela organização para estimular a ação, como também para satisfazer as necessidades e expectativas individuais e profissionais de seus membros (MOTTA, 1989, p. 79).

A teoria organizacional contemporânea aceita, como ponto de partida, que as pessoas desejam desenvolver-se para atingir níveis mais altos de realização pessoal e profissional, assim como possuem grande potencial de aperfeiçoamento. Com relação ao seu trabalho, desejam progredir, aprender novas habilidades e adquirir novos conhecimentos.

Para a condução eficaz de um processo de inovação na organização, Motta apresenta 12 proposições retiradas da teoria gerencial contemporânea, sendo que as sete primeiras referem-se mais a condições organizacionais e as outras cinco a recomendações de natureza individual ao gerente:

1. transfira acentuadamente poder e iniciativa;

2. adote a perspectiva globalista na abordagem de problemas;

3. procure alcançar flexibilidade organizacional e administrativa;

4. favoreça e mantenha comunicações francas e autênticas;

5. crie incentivos e recompensas à iniciativa de mudanças;

6. trate com equidade direitos e prestígios individuais;

7. considere fracassos anteriores e problemas pendentes;

8. destrua a armadilha dos hábitos;

9. olhe para a frente, aventure-se sempre, mas devagar;

Ci. Inf., Brasília, v. 38, n. 2, p. 126-141, maio/ago. 2009 
10. reforce e reconstrua sempre uma postura otimista perante a vida;

11. procure sentir-se útil diante de problemas; veja o que pode fazer para resolvê-los;

12. opte pela ação e pelo desenvolvimento pessoal para destruir os adversários da inovação: comodismo, estabilidade.

Roberts (1985, p. 14), abordando a questão da administração de bibliotecas universitárias americanas, examina dois paradigmas dos bibliotecários acadêmicos - o líder ${ }^{1}$ (estreitamente ligado ao século 19 e seus ideais) e o gerente ${ }^{2}$ (associado à democratização e às novas tecnologias do século 20) - e considera que pode haver uma demanda pela síntese do melhor de ambos os modelos para a liderança na biblioteca deste século 21. Segundo Roberts, os bibliotecários acadêmicos americanos do século 19:

[...] eram sábios com um compromisso com valores humanísticos, professores de livros que tinham o respeito e a consideração tanto do corpo docente quanto dos estudantes [...] eram generalistas e parceiros dos professores no processo educacional [...] eram ligados a uma área de assunto e conectados a um departamento, frequentemente ministrando cursos enquanto, também, dirigiam as bibliotecas [...] Além de participarem de suas atividades profissionais, tais como associações, encontros, discussões e conferências com outros colegas universitários, eram engajados em atividades de áreas relacionadas, tais como clubes de eruditos e sociedades de bibliófilos. Como outros cidadãos educados, eles também estavam engajados em atividades cívicas e responsabilidades que permeavam a sociedade americana durante aquele tempo, tais como clubes de serviço, organizações

\footnotetext{
1 "Líder, o que lidera, como guia, condutor, chefe, comandante."

2 "Gerente, o que administra; diretor, uma pessoa que conduz negócios com economia."
}

filantrópicas e grupos de igreja [...] eram líderes ativos, sábios e humanistas.

Roberts considera que esse modelo de bibliotecário acadêmico tem sua origem associada às características do século 19: "uma era de humanidades, com filosofia e artes em posição elevada no currículo." Apesar de o mundo do conhecimento do século 19 ser caracterizado como enciclopédico, era, segundo Roberts, autocontido. Havia textos clássicos que todas as pessoas educadas conheciam e liam. Havia uma unicidade de propósito e um foco central para a vida acadêmica. $\mathrm{O}$ conhecimento era estável e podia ser dominado.

Assim como a sociedade americana do século 19 refletia em suas bibliotecas uma visão de mundo humanística e erudita que caracterizava a própria época, o autor considera que a sociedade do século 20, caracterizada por "valores instáveis e transições, mudanças sociais e inovações tecnológicas”, imprime seus reflexos nas biblio-tecas acadêmicas atuais e, consequëntemente, na atuação dos bibliotecários.

O mundo do conhecimento tornou-se, segundo Roberts, o mundo de informação, e o bibliotecário acadêmico, de humanista, transformou-se em um especialista. Essa especialização contribui para o crescimento de formas burocráticas de administração inerentes às organizações e instituições complexas atuais. O modelo do bibliotecário universitário, aquele do gerente do século 20 , tem estado sujeito às pressões inerentes às forças e transformações que o originaram.

Roberts ressalta que os gerentes das bibliotecas universitárias atuais precisam estar atentos aos problemas decorrentes de sua atuação em uma instituição burocrática, cuja estrutura reforça a fragmentação e o isolamento de seus membros. Deve procurar sintetizar os atributos positivos do modelo de líder e do modelo de gerente mencionados, no sentido de criar uma administração adequada às necessidades das bibliotecas universitárias modernas. 
Peters e Waterman ${ }^{3}$, citados por Roberts, afirmam que os critérios incluídos na administração das melhores empresas em ação, na América, envolvem conceitos e atitudes afins à sólida performance financeira, à alta qualidade de produtos, à habilidade para inovar e ao alto grau de satisfação tanto de clientes quanto de empregados. Os autores citados constataram que a maior parte dos trabalhadores deseja trabalhar "duro" e produzir um serviço de qualidade. Porém, afirmam que esses desejos são frequentemente frustrados pelas próprias companhias, devido à má administração.

Hayes $^{4}$, também citado por Roberts, notou que os japoneses administram suas companhias bem, insistindo no básico. Fazer as coisas simples e fazêlas bem provou ser uma maneira bem-sucedida, para eles, de administrar. Os gerentes japoneses têm dado bastante atenção aos recursos humanos. Enfatizam o contínuo desenvolvimento das habilidades dos empregados e procuram contratar pessoas que se integrem bem ao grupo e compartilhem valores similares. Os trabalhadores admitidos são tratados como parte da comunidade e da vida da companhia. Há ampla rotatividade de tarefas, avaliação baseada em muitos níveis de critérios, e lenta, porém constante, promoção no emprego. Há um comprometimento com a companhia e seus valores. Os japoneses se preocupam tanto com seus empregados quanto com seus equipamentos e produtos, por verem seus empregados como capital humano. Com programas de enriquecimento de tarefas e atividades de treinamento, os gerentes japoneses conseguem aumentar o valor dos trabalhadores. Tanto para os gerentes quanto para os trabalhadores há lealdade e comprometimento com a companhia, atitudes remanescentes do líder de bibliotecas do século 19 (DRUCKER, 1974).

\footnotetext{
${ }^{3}$ In search of excellence : lessons from America's best-run companies. New York: Harper \& Row, 1982.360 p. Obs.: Em 1995 foi publicado pela editora HarperCollins, de Londres. Existe tradução para o português intitulado: Vencendo a crise: como o bom senso pode superá-la.

${ }^{4}$ HAYES, R. Why japanese factories work. Harvard Business Review, p. 57-66, July/Aug. 1981.
}

Roberts considera que os gestores das bibliotecas acadêmicas atuais devem procurar reestabelecer os ideais de liderança do século 19, no desempenho dos valores da biblioteca universitária do século 20 . Aconselha o replanejamento e a reestruturação de suas organizações, de modo a eliminar as posições que encorajam a impotência e a ineficácia da burocracia. Da mesma forma, recomenda que os bibliotecários acadêmicos se tornem líderes responsáveis, com a visão que caracterizava o mundo do bibliotecário acadêmico do século 19, pois o mundo do século 20 do bibliotecário acadêmico é um mundo de fragmentação cuja [...] visão é confundida com pedaços de sistemas, redes e métodos".

Ainda na visão de Roberts (1985, p. 18), os bibliotecários acadêmicos administradores podem alcançar uma boa administração nesse complexo mundo de hoje, desde que desenvolvam estratégias de longo prazo, cuidadosamente trabalhadas e perseguidas com determinação, através de tempos bons ou ruins. Recomenda o estabelecimento de programas de treinamento e desenvolvimento dos empregados, o deslocamento do processo de decisão para perto do local de implementação, o fortalecimento dos serviços básicos antes de adicionarem outros e o comprometimento e a lealdade para com a visão ou objetivos da organização.

Martell (1989, p. 74) afirma que a natureza do trabalho e seus correspondentes requisitos de performance estão sofrendo profundas mudanças. Isso implica novas discussões a respeito do enfoque a ser dado aos recursos humanos nas organizações.

Os líderes corporativos e políticos americanos estão procurando construir nova estrutura institucional na qual excelência e alta performance sejam adotadas como normas culturais básicas. Para serem bemsucedidos nesse esforço, os líderes têm de criar nova realidade para o empregado, incluindo alta qualidade de vida no trabalho. Entre as questões discutidas pela administração de pessoal praticada atualmente nas bibliotecas americanas, encontram-se 
motivação, desenho do emprego, qualidade de vida no trabalho, cultura organizacional, alta performance, excelência e inovação.

Martell considera que alguns conceitos como produtividade e motivação têm sido comumente aviltados por uma atividade histórica e direcionada que ignorou e até rejeitou as necessidades do trabalhador por uma razoável qualidade de vida no trabalho. Dessa forma, o pensamento administrativo, desde a Revolução Industrial, entende a produtividade "como fazer alguma coisa mais depressa", colocando em segundo plano a preocupação com a qualidade. A motivação tem sido entendida como "uma força externa para ser aplicada sobre o empregado: eu motivei meu pessoal a trabalhar duro." Entretanto, continua Martell, a maioria dos pesquisadores vê a motivação como uma força interna que "energiza, direciona ou sustenta o comportamento". Para Martell, o estado motivacional do empregado pode ser, provavelmente, o mais crítico elemento para se alcançar a excelência, sustentado por pensamento de Herzberg ${ }^{5}$, que acredita que a motivação vem de dentro e não pode ser imposta externamente. Isso reforça a premissa de necessidade de o administrador ou gerente fixar as condições pelas quais a motivação interna do empregado possa ser energizada e sustentada.

Conforme Martell, o "desenho" das tarefas pode motivar os empregados, gerando efeito benéfico sobre a satisfação e a performance. Geralmente, observa o autor, os administradores tendem a tratar os empregados "como instrumentos ou como extensões das máquinas, ignorando as características singulares do empregado, enquanto indivíduo." Considera ainda que os administradores de bibliotecas podem querer que os empregados façam maior investimento pessoal, mas cabe à organização trabalhar junto nesse sentido, para estabelecer um investimento organizacional equilibrado. Esse

${ }^{5}$ HERZBERG, F. One more time: how do you motivate employees? Reprints and coments. Harvard Business Review, v. 65, p. 109-120, Sept./Oct. 1987.

Ci. Inf., Brasília, v. 38, n. 2, p. 126-141, maio/ago. 2009 investimento deveria incluir trabalho projetado para:

- exteriorizar as melhores qualidades em nossos empregados;

- ter alta qualidade de vida no trabalho;

- encorajar a busca de excelência dentro de uma cultura organizacional de alta performance (MARTELL, 1989, p. 79).

Entre as dificuldades colocadas por Martell para que as bibliotecas utilizem os recursos de desenho de tarefas, ele inclui o desconhecimento do profissional a respeito de suas técnicas e a própria complexidade das bibliotecas, que são constituídas por níveis múltiplos (tarefa, função, unidade, departamento, divisão, etc.). Isso exige esforço coletivo e coerente dos seus diversos setores, para que as mudanças pretendidas surtam o efeito esperado, em termos de excelência e alta performance da organização como um todo. Tem sido demonstrado, segundo o autor, que, para propiciar um clima de respaldo para o redesenho do trabalho, os valores organizacionais em relação à biblioteca devem ser favoráveis e coerentes.

Outro aspecto considerado por Martell que influencia a atuação profissional nas organizações diz respeito à qualidade de vida no trabalho. Suttle ${ }^{6}$, citado por Martell, define qualidade de vida no trabalho (QVT) como o grau em que membros da organização de trabalho são capazes de satisfazer importantes necessidades pessoais com suas experiências na organização.

As necessidades pessoais podem ser satisfeitas mediante o "desenho" de funções que inclui as seis principais características de QVT: autonomia, desafio, expressão de criatividade, oportunidade de aprendizagem, participação na tomada de decisão

${ }^{6}$ SUTTLE, J. L. Improving life at work-problems and prospects. In: HACKMAN, J. R.; SUTTLE, J. L. Improving life at work: behavioral approaches to organizational change. Santa Mônica, CA: Goodyear, 1977. 
e uso de uma variedade de valiosos talentos e habilidades.

Hackman (1975) define enriquecimento de tarefa como o processo pelo qual uma pessoa obtém maior controle sobre os fatores que diretamente afetam seu trabalho e sugere que o administrador combine tarefas, forme unidades de trabalho naturais, estabeleça relações com clientes, adicione autonomia e abra canais de "feedback". Efetuando essas mudanças, ele aumentará os níveis de motivação e satisfação, atingirá melhor nível de qualidade de trabalho e alcançará menores graus de absenteísmo e rotatividade.

De algumas das características identificadas como prescritivas das organizações, excelentes autores entre eles, Martell - apontam a necessidade de estar próximo ao cliente.

Tanto a estrutura organizacional das bibliotecas, quanto as normas que regulamentam o seu funcionamento interferem no comportamento e na imagem de seus profissionais, assim como nas possibilidades de acesso aos recursos informacionais nelas armazenados ou disponíveis. Muitas vezes, estruturas organizacionais mal planejadas e normas inflexíveis são causadoras da limitação relacionada ao grau em que as bibliotecas podem e têm sido responsivas às necessidades dos clientes-usuários e da sua própria comunidade de trabalhadores.

O que se faz necessário, de acordo com Martell, é a criação de uma cultura de biblioteca que tenha, entre suas normas básicas, alta performance, serviços e programas responsivos e direcionados para o cliente, forte tendência rumo à inovação e urgência por excelência.

Eliminar deficiências na estrutura organizacional das bibliotecas universitárias e flexibilizar normas profissionais podem tornar essas organizações mais responsivas tanto para a sua clientela de usuários, quanto para sua comunidade de trabalhadores.
Ser responsivo envolve contínuo domínio do ambiente interno e externo a fim de saber sobre necessidades e expectativas da equipe de trabalho e dos usuários clientes, com o objetivo de desenvolver novas posturas gerenciais, assim como desenvolver e implantar programas e serviços em resposta a essas necessidades e expectativas.

Barreiras e dificuldades decorrentes da estrutura organizacional e de normas rígidas, que limitam o grau em que as bibliotecas universitárias podem e têm sido responsivas, só serão realmente eliminadas caso seus gestores estejam preparados, empenhados e dispostos a criar uma cultura organizacional mais comprometida com a satisfação das pessoas, em seu ambiente de trabalho, e de sua clientela de usuários (DUARTE, 2000).

A cultura de uma organização consiste, conforme Martell (1989), dos comportamentos aprendidos e dos significados compartilhados de seus membros e da transmissão destes aos novos membros. $\mathrm{O}$ autor considera que a filosofia tradicional da biblioteconomia, para alcançar excelência, deve buscar um direcionamento competitivo mais semelhante aos negócios e ao esporte. Exemplifica que, em bibliotecas,

[...] curiosamente os bibliotecários de referência medem a quantidade (quantas questões eles recebem por hora), mas não a qualidade (quão efetivamente essas questões são respondidas), enquanto os catalogadores medem a qualidade (quão bem os livros catalogados ajustam-se a padrões relevantes), mas não a quantidade (quantos livros eles catalogam por hora) (MARTELL, 1989, p. 84).

Gib Akin e David Hopelain (1986), destacados pelo autor, enumeram alguns elementos que fazem parte de um ambiente produtivo:

- níveis pessoais internos de iniciativa e excelência;

Ci. Inf., Brasília, v. 38, n. 2, p. 126-141, maio/ago. 2009 
- efetivo trabalho de equipe;

- identificação com a função;

- orientação para os resultados;

- suporte/apoio para as realizações;

- uso autônomo de habilidades;

• vontade de trabalhar "duro".

Construir uma cultura mais produtiva é apenas uma das mudanças culturais que parecem necessárias às bibliotecas. Outras mudanças, em sua cultura, poderiam levar gerentes e respectivas equipes de trabalho a encorajar e facilitar a criatividade, a assumir riscos, a descobrir, dentro de si mesmos, novas fontes de criatividade e motivação que resultassem em benefícios individuais, organizacionais e coletivos.

Os gestores ou gerentes de bibliotecas precisam descobrir novos caminhos e maneiras inovadoras de criar nova cultura bibliotecária a partir de uma cultura consensual.

Estudos recentes indicam que os trabalhadores, de modo geral, estão satisfeitos com seus empregos, mas não com o tratamento dado a eles pela administração. Nas organizações em que as recompensas financeiras são limitadas, há maior premência de se criarem alternativas e ambientes de trabalho mais condizentes com as necessidades internas das pessoas. A realização pessoal, na maioria das vezes, decorre de um excelente trabalho e esforço de equipes.

O sucesso gerencial é baseado em trabalho individual, na condição de gestor, e no trabalho e esforço coletivo de todo o capital humano constituinte das organizações.

Os gestores das bibliotecas universitárias devem ter consciência clara de seu papel. Clara definição do papel profissional é requisito básico para o desenvolvimento de um conjunto bem construído de metas pessoais.

Ci. Inf., Brasília, v. 38, n. 2, p. 126-141, maio/ago. 2009
Sob essa perspectiva, Richard Steers e Lyman Porter, citados por Martell (1989, p. 88), afirmam que cada administrador deveria buscar:

- desempenhar um papel ativo na administração dos processos de motivação no trabalho - mediante comportamento consciente e intencional;

- estar atento quanto às próprias forças e fraquezas e quanto ao seu papel na organização;

- aumentar sua sensibilidade para variações nas necessidades, habilidades e características dos empregados;

- ser capaz de identificar empregados com performance superior e recompensá-los;

- melhorar a clareza de seus subordinados em relação à função e papel;

- aumentar a quantidade de atenção dada à qualidade do ambiente de trabalho, incluindo dinâmica de grupo e clima organizacional;

- avaliar as atitudes do seu pessoal em uma base contínua;

- permitir aos empregados participar mais integralmente em processos destinados a atingir a eficácia organizacional.

Discussões atuais acerca dos termos "administração de pessoal e administração de recursos humanos" e de seus respectivos significados apresentadas por Jin Xudong (2006) mostram que o ponto essencial de diferença entre eles consiste exatamente na filosofia inerente à administração de recursos humanos. Ela coloca as pessoas em primeiro plano, vistas como um recurso propriamente dito. A pessoa é um elemento humano em posição de destaque na organização, um líder que promoverá, através de caminhos consistentes, a construção de alta performance em seus respectivos ambientes de trabalho. A natureza da administração das bibliotecas centrada nas pessoas é humanizada e humanizadora. Transforma a pessoa em principal recurso que a biblioteca possui e usa para prover seus serviços rotineiros, 
assim como para viabilizar a implantação de um planejamento estratégico. Administradores, gerentes ou gestores apresentam-se como administradores de recursos humanos eficientes, quando conseguem mobilizar seu entusiasmo e de outros componentes de sua equipe, de modo a atingir níveis altos de adesão e comprometimento, atraindo iniciativas em prol de seu trabalho. O resultado ideal é uma administração centrada nas pessoas, a fim de criar e desenvolver nova cultura nas bibliotecas, isto é, um ambiente harmonioso no interior de trabalho dessas organizações, conclui Jin Xudong (2006).

Dentre pontos que devem ser considerados pelo grupo de trabalho da biblioteca universitária, o autor destaca os seguintes: colaboração, trabalho em equipe; flexibilidade; cortesia, respeito mútuo; oportunidades de crescimento profissional; apreciação e reconhecimento; honestidade e confiança; autonomia; tratamento igualitário entre as diversas categorias profissionais.

Tendo em vista o objetivo essencial deste trabalho, que incluiu destacar alguns resultados de estudos que pudessem delinear uma visão panorâmica, além de suscitar reflexões acerca dessa questão em contextos das bibliotecas universitárias contemporâneas, serão expostas, a seguir, as últimas considerações sobre o tema.

\section{CONSIDERAÇÕES FINAIS}

A literatura especializada que se consultou para leitura e discussão, apresentada sumariamente neste artigo, mostra caminhos alternativos a seguir por gestores das bibliotecas universitárias dispostos a pensar e agir em prol de mudanças que considerem necessárias e benéficas em suas organizações. A literatura divulgada por esses estudiosos, relativas à gestão de recursos humanos ou capital humano, reflete, em última análise, as expectativas e as exigências da sociedade em termos dos papéis que os administradores deveriam desempenhar perante os contextos nos quais exercem o seu trabalho gerencial. Da mesma forma, ressaltam as expectativas das pessoas trabalhadoras em termos de se dar mais atenção às vertentes humanitárias da administração. Além disso, divulgam técnicas e alternativas que podem auxiliar os gestores ou aqueles que lideram as bibliotecas universitárias a rever sua prática e postura profissionais em prol da performance da organização e das pessoas que nelas trabalham.

Entre as responsabilidades dos gestores das bibliotecas universitárias, estã os cuidados relacionados à contratação de bibliotecários bem qualificados e em número adequado às necessidades do setor; às ofertas de oportunidades de capacitação, qualificação contínua, às ofertas de apoios e de manifestação de reconhecimento dos progressos individuais dos trabalhadores, à promoção de avaliações periódicas da performance e à satisfação de sua equipe de trabalho. São questões importantes que devem ser assumidas pelos gerentes de bibliotecas.

Embora parte razoável dos documentos apresentados neste artigo date das décadas de 80 e 90 do século passado, confrontando-os com vários trabalhos mais recentes sobre a temática, tanto constantes da literatura nacional quanto da internacional, constataram-se a atualidade de seus conteúdos e a pertinência dos tópicos destacados. Os conteúdos integram pautas de discussões e constituem linhas de pesquisas, focos de estudos e de pesquisas em andamento, criação de publicações periódicas ou de fascículos especiais, tendo entre tema central abordagem dedicada a assuntos como "gestão de capital humano em organizações, gestão de talentos, gestão de informação e do conhecimento, gestão de pessoas, gestão com pessoas, gestão de bibliotecas ou unidades de informação, administração participativa", entre outros, que comprovam a relevância crescente da administração de recursos humanos para as ciências sociais (TRANSINFORMAÇÃO, 2000; FERNANDEZ-ALLES; RAMOSRODRIGUES, 2009).

As proposições expressas em documentos mais recentes, registradas em artigos e outros tipos de documentos e publicadas a partir do ano 2000, alertam os gerentes das bibliotecas universitárias ou

Ci. Inf., Brasília, v. 38, n. 2, p. 126-141, maio/ago. 2009 
acadêmicas quanto à importância que deverá ser dada ao trabalho de conscientização e de sensibilização das autoridades governamentais e universitárias, em prol do desenvolvimento harmonioso dessas unidades de informação, que devem se engajar em novos modelos educacionais idealizados para a sociedade da informação, do conhecimento e da aprendizagem (PESTANA, 2003).

Dotar essas instituições de gestores ou líderes capazes de superar desafios estruturais das mais diversas ordens, conciliar interesses conflitantes e adversos, de modo a alcançar a convergência entre interesses imperativos universais, organizacionais e individuais, constitui talvez o maior desafio coletivo desse limiar do século 21.

Modificam-se culturas das bibliotecas a partir da mudança de atitudes das organizações que as sustentam, das pessoas que as gerenciam e das demais equipes que nelas desenvolvem suas atividades profissionais.

Estar atento às marcas que parecem delimitar transições entre século 20 e 21 também compete aos responsáveis pelas bibliotecas universitárias atuais. A realidade que se apresenta nos ambientes de trabalho contemporâneos parece comprovar a existência de um descompasso com o desenvolvimento tecnológico já alcançado, que deveria propiciar o surgimento de uma nova humanidade, unificada "graças ao desenvolvimento técnico, base sólida para uma ação humana mundializada", e não perversa, tirana e competitiva como se apresenta em era da globalização (SANTOS, 2001).

Recomenda-se, portanto, às instituições, aos gerentes e às equipes de trabalho, empenharem-se, ao máximo, a fim de dominar conhecimentos multidisciplinares e humanizadores, que os levem a alcançar a sabedoria necessária, de modo a alcançar objetivos sociais coletivos, justos e legítimos, superando os desafios impostos às agências sociais e às pessoas, nesses tempos de globalização, totalitarismo, sociedade da informação, sociedade do conhecimento e da aprendizagem, era da competitividade acirrada e dos apelos à produtividade exacerbada...

Até o momento em que uma realidade for vista como algo imutável, superior às forças de resistência dos indivíduos que assim a vêem, a tendência destes será adotar uma postura fatalista e sem esperança. Ainda mais e por isso mesmo, sua tendência é procurar fora da própria realidade a explicação para a sua impossibilidade de atuar (FREIRE, 1986).

Artigo submetido em 26/11/2008 e aceito em 16/07/2009.

\section{REFERÊNCIAS}

AKIN, G.; HOPELAIN, D. Finding the culture of productivity. Organizational Dynamics, v. 14, p. 19-32, Winter 1986.

ALMEIDA, Daniela Pereira dos Reis de. Aprendizagem organizacional em ambientes informacionais. In: VALENTIM, Marta (Org.). Gestão da informação e do conbecimento no âmbito da ciência da informação. São Paulo: Polis; Cultura Acadêmica, 2008. cap. 4, p. 55-69.

BARRIONUEVO ALMUZARA, L. La Biblioteca Universitaria de León: pasos hacia la convergencia Europea. In: CONGRESO ISKOESPAÑA, 8., León. Proceedings... Disponível em: $<$ http://eprints.rclis. org/archive/00012707/>. Acesso em: 10 ago. 2008.

BERTOLIN, Júlio C. G. Indicadores em nível de sistema para avaliar o desenvolvimento e a qualidade da educação superior brasileira. Avaliação, Campinas, Sorocaba, v. 12, n. 2, jun. 2007. Disponível em: <http://www.scielo.br/scielo.php?script=sci_arttext\&pid= S1414-40772007000200007\&lng $=p t \& n r m=i$ so $>$. Acesso em: 22 abr. 2009.

CHIAVENATO, I. Introdução à teoria geral da administração: edição compacta. Rio de Janeiro: Campus, 2000.

DRUCKER, P. Management. New York: Harper \& Row, 1974.

DUARTE, E. N. et al. A cultura organizacional influenciando o comportamento do capital humano da biblioteca universitária. Informação \& Sociedade: Estudos, João Pessoa, v. 10, n. 2, 2000. Disponível em: < http://www.ies.ufpb.br/ojs2/index.php/ies/ article/view/333/255 >. Acesso em: 5 ago. 2008.

FERNANDEZ-ALLES, Mariluz:; RAMOS-RODRÍGUEZ, Antonio. Intellectual structure of human resources management research: a bibliometric analysis of the Journal Human Resource Management, "1985-2005". Journal of the American Society for Information Science and Technology, v. 60, n. 1, p.161-175, 2009.

FIÚZA, M. M.; PAIM, I.; FERREIRA, M. L. A. G. Curso de especialização em administração de bibliotecas universitárias. In: SEMINÁRIO NACIONAL DE BIBLIOTECAS UNIVERSITÁRIAS, 5., Porto Alegre, 1987. Anais... Porto Alegre: Biblioteca Central da UFRGs, 1987. v. 1, p. 47-63. 
FREIRE, P. Educação e mudança. 11. ed. Rio de Janeiro: Paz e Terra, 1986.

HACKMAN, J. R. et al. A new strategy for job enrichment. California Management Review, v. 17, p. 57-71, Summer 1975.

HARBOE-REE, Cathrine. Just advanced librarianship: the role of academic libraries as publishers. Australian Academic \& Research Libraries, v. 38, n. 1, p. 16-25, Mar. 2007.

HAVELOCK, R. G. Information professionals as change agents. Drexel Library Quarterly, v. 13, n. 2, p. 48-61, Apr. 1977.

MACEDO, Arthur Roquete de. et al. Educação superior no século XXI e a reforma universitária brasileira. Ensaio: Avaliação e Políticas Públicas em Educação, Rio de Janeiro, v. 13, n. 47, jan. 2005. Disponível em: <http://www.scielo.br/scielo.php?script= sci_arttext\&pid $=$ S0104-40362005000200002\&lng $=$ pt\&nrm $=$ iso $>$. Acesso em: 20 out. 2008.

MARTELL, C. Achieving high performance in library work. Library Trends, Urbana, v. 38, n. 1, p. 73-91, Summer 1989.

MESSEDER, J. E. C. Recursos humanos e transformação social: onde se encontram os desafios? Revista de Administração Pública, Rio de Janeiro, v. 23, n. 4, p. 49-61, ago./out. 1989.

MiCHElOTTO, Regina Maria; COELHO, Rúbia Helena; ZAINKO, Maria Amélia Sabbag. A política de expansão da educação superior e a proposta de reforma universitária do governo Lula. Educar em Revista, Curitiba, n. 28, dez. 2006. Disponível em: $<$ http://www.scielo.br/scielo.php?script= sci_arttext\&pid=S0104$40602006000200012 \& \operatorname{lng}=$ pt\&nrm $=$ iso $>$. Acesso em: 20 out. 2008

MOTTA, P. R. Gerência de ideias novas: como despertar a criatividade e vencer a impotência do desejo inovacional? Revista de Administração Pública, Rio de Janeiro, v. 23, n. 4, p. 71-86, ago./out. 1989.

NEVES, I. C. B. O bibliotecário e o atual contexto social. Revista de Biblioteconomia e Comunicação, Porto Alegre, v. 1, n. 1, p. 23-27, jan./ jun. 1986.

ODDONE, N. O profissional da informação e a mediação de processos cognitivos: a nova face de um antigo personagem. Informação e Sociedade: Estudos, v. 8, n. 1, p. 25-41, 1998.

OLIVEIRA, A. M. et al. Gerenciamento do capital humano em bibliotecas ou centros de informação: desafio imposto pela sociedade do conhecimento. Transinformação, Campinas, v. 12, n. 2, p. 7-16, jul./ dez. 2000.

ORGANIZACIÓN DE LAS NACIONES UNIDAS PARA LA EDUCACIÓN, LA CIÊNCIA Y LA CULTURA (UNESCO). Hacia las sociedades del conocimiento. Informe mundial de la UNESCO. 2005. Disponível em: <http://unesdoc.unesco.org/images/0014/001419/141908s. pdf $>$. Acesso em: 29 jun. 2009.

PASQUARELLI, M. L. R. Análise da estrutura organizacional das bibliotecas universitárias. In: SEMINÁRIO NACIONAL DE BIBLIOTECAS UNIVERSITÁRIAS, 5., Porto Alegre. Anais... Porto Alegre: Biblioteca Central da UFRGS, 1987. v. 2, p. 91-254.
PESTANA, M. C. et al. Desafios da sociedade do conhecimento e gestão de pessoas em sistemas de informação. Ciência da Informação, Brasília, v. 32, n.2, p. 77-84, maio/ago. 2003. Disponível em: < http://www. scielo.br/scielo.php?pid $=$ S0100-19652003000200009\&script $=$ sci arttext\&tlng=es>. Acesso em: 20 jul. 2008.

RENDÓN ROJAS, Miguel Angel. Los valores sociales y políticos dentro del paradigma bibliotecológico en la era de la información. Transinformação, Campinas, v. 19, n.1, p. 9-18, jan./abr. 2007.

ROBERTS, A. F. The academic librarian as leader or manager. The Journal of Academic Librarianship, v. 11, n. 1, p. 14-18, Mar. 1985.

ROBREDO, J.; CUNHA, M. B. da. Documentação de hoje e de amanhã: uma abordagem informatizada da biblioteconomia e dos sistemas de informação. 2. ed. rev. ampl. Brasília: Ed. do Autor, 1986. $400 \mathrm{p}$.

ROZADOS, Helen Beatriz Frota. O bibliotecário brasileiro e a formação continuada: a ação do Conselho Federal de Biblioteconomia. In: CONGRESO IBEROAMERICANO DE BIBLiOTECOLOGÍA, 2., 2007, Buenos Aires. [Anais...] Disponível em: <http://www.cfb.org.br/html/sala_leitura/arquivos/Congreso_ Bibliotecologia.pdf>. Acesso em: 20 nov. 2008.

SANTANA, I. V. Biblioteca universitária e transferência da informação: problemas e perspectivas. Ciência da Informação, Brasília, v. 18, n. 1, p. 35-44, jan./jun. 1989.

SANTOS, M. Por uma outra globalização: do pensamento único à consciência universal. Rio de Janeiro: Record, 2001.

SILVA, S. M. G. Qualidade nas bibliotecas universitárias: a influência dos objetivos organizacionais. Informação \& Sociedade: Estudos, João Pessoa, v. 10, n.1, 2000. Disponível em: <http://www.ies.ufpb.br/ ojs2/index.php/ies/article/view/342/264>. Acesso em: 10 ago. 2008.

SILVEIRA, J. G. da. Bibliotecário acadêmico: papéis atribulados pelo ritmo descompassado entre o ambiente universitário e suas bibliotecas. 1991. 172 p. Dissertação (Mestrado)- Escola de Biblioteconomia da UFMG, Belo Horizonte, 1991.

STEERS, R. M.; PORTER, L. W. Motivation and work behavior. New York: McGraw-Hill, 1975.

TACHIZAWA, Takishy; FERREIRA, Victor Cláudia Paradela; FORTUNA, Antônio Alfredo Mello. Gestão com pessoas: uma abordagem aplicada às estratégias de negócios. 2. ed. São Paulo: FGV, 2001.

TRANSINFORMAÇÃO. Gestão de talentos (número especial), Campinas, v. 12, n.2, jul./dez. 2000. Publicação da Pontifícia Universidade Católica; Programa de Pós-Graduação em Biblioteconomia.

XUDONG, Jin. Human touch of library management in the United States: personal experiences of creating and developing a harmonious environment. Chinese Librarianship: an International Electronic Journal, n. 22, Dec. 2006.

Ci. Inf., Brasília, v. 38, n. 2, p. 126-141, maio/ago. 2009 


\section{OUTROS DOCUMENTOS CONSULTADOS}

BRANDÃO, G. R. Gestão de pessoas e as universidades corporativas: dois lados da mesma moeda? Revista de Administração de Empresas RAE, São Paulo, 46, n. 2, p. 22-33, abr./jun. 2006.

CHIAVENATO, I. Recursos humanos: o capital humano das organizações. 8. ed. São Paulo: Atlas, 2004. 515 p.

OLIVEIRA, S. M. de. Correlação entre atuação de gerentes de S. I. e aspectos gerenciais considerados importantes. Transinformação, Campinas, v. 12 , n. 2, p. 29-50, jul./dez. 2000.

RAMALHO, F. A. Configuração das bibliotecas universitárias do Brasil face às novas tecnologias da informação. Informação \& Sociedade: Estudos, João Pessoa, v. 2, n. 1, p. 29-37, jan./dez. 1992. Disponível em: < http://www.ies.ufpb.br/ojs2/index.php/ies/ article/view/41/1348>. Acesso em: 5 jul. 2008. 